The blood pressure returned to hypertensive values only three weeks after recovery of an intact renin angiotensin system. This is surprising even though it is known that continuous control of blood pressure can be achieved despite intermittent resumption of normal angiotensin converting enzyme activity. ${ }^{5}$

We thank Dr M Hichens and Dr E H Ulm (Merck, Sharp and Dohme Research Laboratories, USA) for measuring the serum concentration of enalaprilic acid and Mrs A F Stale for typing the manuscript. This work was supported in part by grants from the Swiss National Science Foundation.

${ }^{1}$ Biollaz J, Burnier M, Turini GA, et al. Three new long-acting converting enzyme inhibitors: relationship between plasma converting enzyme activity and response to angiotensin I. Clin Pharmacol Ther $1981 ; 29$ : $665-70$.

${ }^{2}$ Biollaz J, Brunner HR, Gavras I, Waeber B, Gavras H. Antihypertensive therapy with MK 421: angiotensin II-renin relationships to evaluate efficacy of converting enzyme blockade. $\mathcal{F}$ Cardiovasc Pharmacol 1982; 4:966-72.

${ }^{3}$ Turini GA, Waeber B, Brunner HR. The renin-angiotensin system in refractory heart failure: clinical, hemodynamic and hormonal effects of captopril and enalapril. Eur Heart $\mathcal{F} 1983 ; 4$, suppl A:189-97.

4 Biollaz J, Schelling JL, Jacot des Combes B, et al. Enalapril maleate and a lysine analogue (MK-521) in normal volunteers; relationship between plasma drug levels and the renin angiotensin system. $\mathrm{Br} \mathcal{F}$ Clin Pharmacol 1982;14:363-8.

5 Waeber B, Brunner HR, Brunner DB, Curtet AL, Turini GA, Gavras H. Discrepancy between antihypertensive effect and angiotensin converting enzyme inhibition by captopril. Hypertension 1980;2:236-42.

(Accepted 13 October 1983)

Division of Nephrology and Hypertension, University Hospital, Lausanne, Switzerland

B WAEBER, MD, privat docent

J NUSSBERGER, MD

H R BRUNNER, MD, associate professor of medicine

Correspondence to: Dr H R Brunner.

\section{Prognostic importance of hyperglycaemia induced by stress after acute myocardial infarction}

Transient hyperglycaemia is a recognised finding during acute myocardial infarction and is considered to be related to stress. On clinical signs alone hyperglycaemia induced by stress cannot be differentiated from undiagnosed diabetes mellitus. In this study we measured haemoglobin $A_{1}$ concentrations to differentiate between the two conditions. Hyperglycaemia induced by stress in acute myocardial infarction was then related to prognosis using the coronary risk index of Peel et al (a prognostic index for grading the severity of infarction based on sex, age, ischaemic history, shock, heart failure, and electrocardiographic changes; a score of $\geqslant 17$ is associated with a $50 \%$ risk of death).

\section{Patients, methods, and results}

We studied 110 patients admitted to hospital with suspected acute myocardial infarction. They were examined on admission and note made of pulse rate, blood pressure, cardiac rhythm, and the presence or absence of shock or cardiac failure. The examination was repeated on days 1,2 , and 10 after admission. Blood glucose concentrations were measured on admission and after fasting on days 1 to 5 . Haemoglobin $A_{1}$ concentrations were measured on days 1 and 3 . All patients who had hyperglycaemia and survived, other than those known to have diabetes, were reviewed three months later, when haemoglobin $A_{1}$ concentrations were measured. Glucose tolerance tests were also performed at that time by measuring blood glucose concentrations on fasting and one and two hours after ingestion of $75 \mathrm{~g}$ glucose.

In the assay of haemoglobin $A_{1}$ concentrations red cells were diluted in a ratio of $1: 10$ with physiological saline and incubated overnight before formation of the haemolysate. The assay was then performed using a Biorad column test kit (catalogue No 191-7001). Blood samples taken from 40 healthy laboratory staff two hours after a meal gave a normal range of $4.5-7 \%$; in all samples the glucose concentrations were lower than $7.3 \mathrm{mmol} / \mathrm{l}(132 \mathrm{mg} /$ $100 \mathrm{ml})$.

Acute myocardial infarction, defined according to criteria of the World Health Organisation, ${ }^{2}$ was confirmed in 61 patients, 21 of whom $(34 \%)$ had hyperglycaemia compared with four of the $49(8 \%)$ without acute myocardial infarction $\left(\chi^{2}=9 \cdot 2 ; \mathrm{df}=1 ; \mathrm{p}<0.01\right)$ (figure). Only one patient with acute myocardial infarction had a raised haemoglobin $A_{1}$ concentration $(11 \%)$ and died during the acute phase. Fourteen patients died during admission and a further four during the follow up, giving a total death rate of $30 \%$. Hyperglycaemia was then related to prognosis using the Peel index. The death rates after acute myocardial infarction were $57 \%(12 / 21)$ in patients with hyperglycaemia induced by stress and $15 \%(6 / 40)$ in those without $\left(\chi^{2}=\right.$ $9 \cdot 8 ; \mathrm{df}=1 ; \mathrm{p}<0.01)$. A Peel index of $\geqslant 17$ was found in 17 out of 21 patients $(80 \%)$ with and six out of 40 patients $(15 \%)$ without hyperglycaemia $\left(\chi^{2}=\right.$ $22.8 ; \mathrm{df}=1 ; \mathrm{p}<0.001$ ). Among 49 patients who did not suffer acute myocardial infarction four had hyperglycaemia induced by stress; all four presented with acute left ventricular failure. One died during follow up. Ultimately haemoglobin $A_{1}$ concentrations were measured and glucose tolerance tested in 12 patients who had hyperglycaemia induced by stress and survived. The results of both tests were normal in 10 patients and indicative of diabetes in two, one of whom had a haemoglobin $A_{1}$ concentration of $7 \cdot 7 \%$.

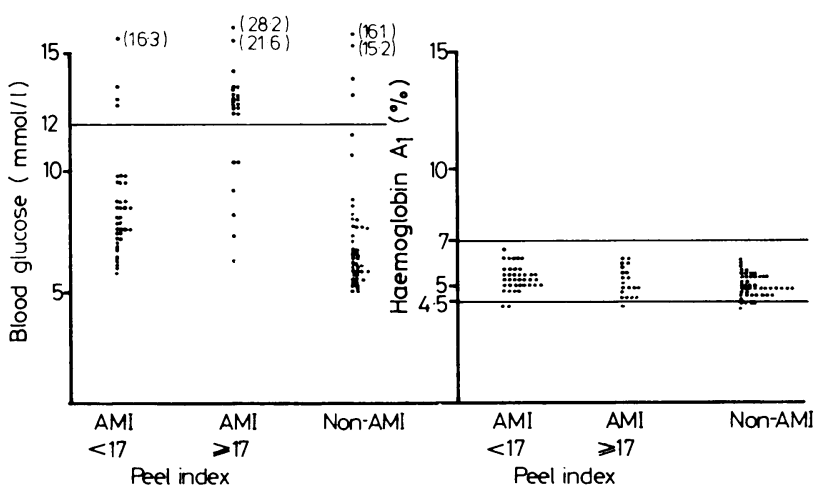

Haemoglobin $A_{1}$ and blood glucose concentrations in patients on admission with and without acute myocardial infarction (AMI). Patients with Peel index $\geqslant 17$ are compared with those with Peel index $<17\left(\chi^{2}=9 \cdot 2 ; \mathrm{df}=1\right.$; $p<0.01$ ). Horizontal lines indicate upper limit of normal glucose concentration and normal range of haemoglobin $A_{1}$ concentration. The four patients without AMI whose blood glucose concentrations were above the normal range had left ventricular failure.

Conversion: SI to traditional units-Glucose: $1 \mathrm{mmol} / 1 \approx 18 \mathrm{mg} / 100 \mathrm{ml}$.

\section{Comment}

Our study showed that hyperglycaemia is common after acute myocardial infarction whereas high haemoglobin $A_{1}$ concentrations are less common. Accordingly, routine measurement of haemoglobin $A_{1}$ concentrations in patients thought to have hyperglycaemia induced by stress is unlikely to be helpful despite a previous suggestion that it is of value for early interpretation of hyperglycaemia after acute myocardial infarction. ${ }^{3}$ We also showed that hyperglycaemia induced by stress is associated with poor prognosis in patients who have had acute myocardial infarction. Follow up of such patients suggested that hyperglycaemia induced by stress is a temporary phenomenon in patients with otherwise normal carbohydrate tolerance, contrary to previous findings. ${ }^{4}$ We conclude that hyperglycaemia induced by stress should be considered to be a crude prognostic marker in acute myocardial infarction indicating poor prognosis and high mortality.

We thank Dr J Ireland for his advice during this study and Miss E Paton for preparing the manuscript.

1 Peel AAF, Semple T, Wang I, Lancaster WM, Dall JLG. A coronary prognostic index for grading the severity of infarction. $\mathrm{Br}$ Heart $\mathrm{f}$ $1962 ; 24: 745-60$.

2 Expert Committee on Cardiovascular Disease and Hypertension. Hypertension and coronary heart disease: classification and criteria for epidemiological studies. WHO Tech Rep Ser 1959;No 168:1-325.

${ }^{3}$ Soler NG, Frank $S$. Value of glycosylated haemoglobin measurements after acute myocardial infarction. $\mathcal{F} A M A 1981 ; 246: 1690-3$.

${ }^{4}$ Husband DJ, Alberti KGMMM, Julian DG. Stress induced hyperglycaemia during acute myocardial infarction: an indicator of pre-existing diabetes. Lancet 1983 ;ii:179-81.

(Accepted 3 October 1983)

Royal Alexandra Infirmary, Paisley, Renfrewshire PA2 6LX

A LAKHDAR, MB, MRCP, medical registrar

P STROMBERG, MB, MRCPATH, consultant biochemist

S G MCALPINE, MD, FRCP, consultant physician

Correspondence and reprint request sto: Dr A Lakhdar, registrar in medicine, endocrinology, and diabetes, Stobhill General Hospital, Glasgow G21 3UW 